
\title{
28 Research Suare \\ Dynamic effects of Sudanese low pressure on moisture feeding in Iran
}

vahideh sayad ( $\square$ sayadvahideh@gmail.com )

Kharazmi University https://orcid.org/0000-0002-6924-7656

zahra hejazizadeh

bohloul alijani

mohammad saligheh

\section{Research Article}

Keywords: Sudanese low pressure, Atmospheric river, atmospheric thermodynamics, temperature gradient, precipitation

Posted Date: March 16th, 2021

DOl: https://doi.org/10.21203/rs.3.rs-248639/v1

License: (c) (1) This work is licensed under a Creative Commons Attribution 4.0 International License.

Read Full License 


\section{Abstract}

- The Sudanese low pressure systems is one of the thermal low pressures that are formed around the Red Sea and their low-pressure lines cover the south of the Red Sea, Sudan, and Ethiopia and continue their route through the southwest of Iran and cause heavy rainfall. The common feature of all these rain systems is land surface low pressures or low altitudes of higher levels. For dynamic and thermodynamic analysis of the mechanism of precipitation caused by the Sudanese low-pressure system, the climate maps containing data of $u$ wind, $v$ wind, omega, Shum, slp, monthly average of northward surface stress, daily mean precipitation rate, and temperature from 1988-2020 during the cold season of the year were applied. The results show that the Sudanese low-pressure core has the largest extent in 1999, 2006, and 2011. During this period, from the Sudanese region to the upper latitudes of Iran, the element of northward surface stress had good potential. The study showed that jet streams create rivers that originate in Africa and are reinforced by Sudanese low pressure and transfer moisture to the upper atmosphere of Iran. Between the positive and negative omega contours of about $600 \mathrm{hPa}$, the horizontal moisture transfer mechanism for Iran's rainfall is created by atmospheric rivers reinforced by Sudan's moisture core. High-temperature gradients in isothermal lines in the range of $550-850 \mathrm{hPa}$ also occurred on the same day. Finally, the precipitation map shows a relatively good rainfall by atmospheric river above Iran.

\section{Introduction}

Identifying tropical cyclones and determining and defining cyclones and their paths have been challenging topics among climatologists. In one of the first studies on extraterrestrial cyclones, the frequency of cyclonic and anticyclonic centers as well as the destruction centers of these atmospheric systems in the Northern Hemisphere were studied (Smagorinsky, 1950). Some preliminary studies have shown that the North Atlantic, especially its west and east, the North Pacific and the Mediterranean Basin, especially during the cold period of the year, are the main cyclonic centers in the Northern Hemisphere (Withaker and Horn, 1984). In early studies, a cyclone was manually identified and routed from synoptic maps, which was a time-consuming task (Flocas et al., 2010); However, due to the introduction of computers into the world of science, automated and machine methods caused cyclones to be identified and routed objectively and intuitively on digital maps (Ulbrich et al., 2009). Routing cyclones can be a useful tool for classifying them based on their size (Rudeva and Gulev, 2007), their physical properties (Blender et al., 1997), and the degree of disturbances they cause in the atmosphere. Due to the lack of a single scientific definition of extraterrestrial cyclones, a large number of identification and routing methods have been developed (Neu et al., 2013).

The first objective method for Mediterranean cyclones was introduced by Alpert et al. (1990). In their study, they used the ECMWF data based on monthly data of a 5-year period (1982-1987) to analyze the cyclone frequencies and cyclonic tracks with a low temporal and spatial resolution (12-hour temporal resolution and $2.5^{\circ}$ spatial resolution). For this purpose, the minimum level of geopotential height of 
elliptical search area was used to determine the cyclone in the next step, the main axis of which was determined using a wind vector of $700 \mathrm{hPa}$. A slope gradient of $0.5 \mathrm{hPa}$ at $500 \mathrm{~km}$ was defined as the criterion for cyclone detection in four directions (north, south, east, and west).

Blender et al. (1997) used a two-step approach to identify mid-latitude cyclones and cyclone paths in the North Atlantic. The authors first considered the minimum altitude geopotential pressure of sea level as a cyclone. This minimum pressure zone should have occurred at least in a $3 \star 3$ grid range with a spatial resolution of $1.1 * 1.1$ and also, the next criterion was the average positive altitude slope, which was a slope of $200 \mathrm{~m}$ per $1000 \mathrm{~km}$. After identifying the cyclones and clustering them by the k-mean method, the cyclones were clustered into three types of cyclone tracks. The first type was stationary cyclones that did not have a clear and long path and their field of activity was mostly around the place of their formation. The second group of cyclones was identified as North-eastward Cyclones. The general path for them to move was from the formation place in the North Atlantic to the Northeast, and finally, the zonal cyclones, which moved east and west with a shorter spatial and temporal range, and seemed to have limited regional activity.

In another study, Sinclair (1997) used ECMWF rotation data to intuitively identify and route twohemisphere cyclones and showed that they are formed and intensified in the Northern Hemisphere, near the east coast of the seas in Asia and North America. In the Southern Hemisphere, cyclones are formed in mid-latitudes and on the oceans off the east coast of South America and Australia, and they decay in high latitudes. Mehmet et al. (2004) studied the variability of cyclonic paths in Turkey and showed that the dominant cyclonic paths were five paths with the highest frequency of cyclones occurring in winter. Picornell et al. (2001) identified and routed western Mediterranean cyclones for the period 1995-1999 with a high-resolution (0.5). To eliminate weak and small systems, they set the criterion of pressure slope of 0.5 hectopascals per 100 kilometers in 6 directions.

Trigo (2006) in a study on the number and intensity of cyclones in Europe and the North Atlantic showed that cyclones in the Azores and the Mediterranean had a decreasing trend and they had an increasing trend at higher latitudes. Romem et al. (2007) showed that only $13 \%$ of the cyclones entered the Mediterranean, while 87\% were generated in the Mediterranean Basin. According to the authors, the entering cyclones originated in three different regions: the Sahara Desert (6\%), the Atlantic Ocean (4\%), and Western Europe (3\%). It should be pointed that most of the cyclones that enter the Mediterranean Basin from the Sahara Desert reach the eastern coasts of the basin, while a small percentage of Atlantic cyclones reach the eastern Mediterranean Basin and none of the cyclones from Western Europe entering the Mediterranean basin, are able to reach the eastern coasts of the basin.

Simmonds et al. (2008), studying the behavior and characteristics of cyclones in the Arctic (the domain north of $70^{\circ} \mathrm{N}$ ), investigated the climate change in the region in relation to changes in cyclone behavior and showed that the highest density of cyclones was in Norway and Svalbard and the Barents and Kara Seas. They also found that the number of cyclones increased more in winter than in summer. In a study condunted hv Nell et al (2013) with fifteen different mothods in the two hemispheres to identify and route Loading [MathJax]/jax/output/CommonHTML/fonts/TeX/fontdata.js 
cold season cyclones, the authors concluded that the number of cyclone centers in the Northern Hemisphere during the 20-year statistical period (1989-2009) had a significant upward trend. While the number of deep cyclones has been decreasing, and in some methods, this trend has been significant. However, they showed that the number of paths, their lifespan, and the intensity of cyclones may vary, depending on the type of algorithm used. This discrepancy in the results may indicate that there is no comprehensive and universal definition of a cyclone. As another important result of their work, one can claim that a particular algorithm does not have a higher priority than other approaches.

In another work by Kelemen et al. (2014) on cyclone formation in the Mediterranean region, the authors showed a significant increase in cyclone formation in the region during the statistical period of 19812000. Flaounas et al. (2014) used the relative rotation data at $850 \mathrm{hPa}$ of the European Medium-Term Forecast Center, with a 6-hour temporal resolution and 1.5 degrees spatial resolution during the period 1989-2009, to identify and route northern hemisphere cyclones in the winter. In the algorithm used, they considered the center of the cyclone as the maximum relative rotation or the maximum wind speed, or the minimum sea surface pressure. Some studies have also examined the relationship between cyclones and severe weather events such as heavy rainfall and strong winds (Reale and Lionello, 2013). Winter cyclones associated with heavy rainfall originate from different parts of the Mediterranean basin. If heavy rainfall occurs in the northwestern part of the Mediterranean basin, the existing cyclones are mostly from the North Atlantic. In the eastern part of the Mediterranean, cyclones form in the Mediterranean Sea itself, mainly with Cypriot origin, while in the southern part of the sea, heavy rainfall occurs due to cyclones forming in North Africa. The authors also showed that heavy rainfall is associated with the negative phase of North Atlantic fluctuations and the East-Atlantic West-Russia pattern.

Ramis et al. (1998) studied the heavy rains and floods that occurred on 9 and 10 October 1994 in Catalonia (Spain) and showed that the cyclone formed in the western Mediterranean with the orographic forcing led to more than $400 \mathrm{~mm}$ of rain and consequently heavy flooding in southern Catalonia. Later, Campins et al. (2006) studied the relationship between Mediterranean cyclones and heavy rainfall and strong winds. They found a strong link between cyclonic centers in the Balearic Islands in southern Italy and the coasts of Catalonia on the Iberian Peninsula, and extreme events such as heavy rainfall and strong winds in the region.

Bech et al. (2011) investigated floods and storms that occurred on the 2nd of November 2008 in the southern coast of Catalonia (NE Spain). The authors considered flooding during a day, which totaled more than $100 \mathrm{~mm}$, and there was $40 \mathrm{~mm}$ precipitation in half an hour, as a tornadic flood, and concluded that this hazard was associated with a cyclone and strong low-pressure formed in the Iberian Peninsula. Some researchers have also pointed to frontless low-pressures that extend from the Red Sea and Sudan to the eastern Mediterranean and southwest Asia, causing torrential rains in these areas (Alpert et al., 2004).

In Iran, few studies have been carried out on cyclones. The first study was conducted by Alijani (1987). He invectinated the relationchin hetween the cnatial dictribution of cyclonic routes in the Middle East and Loading [MathJax]/jax/output/CommonHTML/fonts/TeX/fontdata.js 
high-level air systems. The results of this study showed that the effect of high-level systems on the dispersion of cyclonic routes in the Middle East is much greater and more important than the role of roughness as well as the pattern of surface pressure. Irannejad et al. (2009) investigated the effect of the annual frequency of cyclones of Mediterranean cyclonic centers on the annual rainfall of Iran in the statistical period of 1960-2002. The results of their study showed that except for the southeastern, eastern, and parts of central Iran, the annual rainfall in other parts of the country is significantly affected by the frequency of cyclones in these centers.

Hejazizadeh and Sedaghat (2009) identified the routes of the Middle East cyclones in the cold period of the year digitally and during the period of 1993-2002 and identified the five main routes and showed that the highest frequency of cyclones enters from the west and northwest of Iran. Another noteworthy result is that the most important route is the Central West originating in Cyprus. Khosravi et al. (2010) studied the temporal and spatial position of cyclones affecting Iran on a monthly and seasonal scale for one year and concluded that the peak period of Mediterranean cyclone activity was December and February and in winter, the Italian cyclonic centers transfer to the eastern half of the sea and Cyprus, Syria and Turkey.

The first study focusing on the low-pressures of the Red Sea region with regard to Iran was an article by Olfat in 1968 (as cited in Mofidi and Zarrin, 2005). In this article, the author points to the low pressures that are formed in North Africa and the Red Sea, which, after crossing Saudi Arabia and the Persian Gulf, are causing precipitation in Iran. Lashkari (2002) studied the routing of Sudanese low-pressure systems entering Iran. He showed that Sudanese systems enter Iran from five major routes and cause rainfall. Farajzadeh et al. (2008) by routing and finding the frequency of rainfall systems in western Iran concluded that the largest number of rainfall systems causing rain in the region were Sudanese systems and Mediterranean-Sudanese integrated systems were of secondary importance. They also concluded that only Sudanese systems have a rainfall of more than $300 \mathrm{~mm}$.

Lashkari et al. (2008) through a synoptic study of the causes of flooding in Golestan province concluded that five types of air masses and pressure systems are effective in precipitation in the southeast of the Caspian Sea, one of which is the Sudanese low pressure system. Azizi et al. (2009) performed a synoptic analysis of heavy rainfall in the west of the country. For this purpose, they had a case study of the precipitations of March 7-15, 2007. The results of the study showed that the low pressure system of the Mediterranean Sea and the Sudanese low pressure tongue caused the rains of this period and the Mediterranean Sea, the Black Sea and the Red Sea have played a role in strengthening these systems on the land surface. In addition, it was found that on the day that the peak rainfall occurred, the Mediterranean low-pressure system entered the country from the northwest and the Sudanese lowpressure system entered from the southwest and they merged.

Parandeh Khozani and Lashkari (2010) made a synoptic study of flooding systems in southern Iran. For this purpose, they selected 20 severe floods and divided them into 4 patterns and categorized them. The results of their study showed that the storms that lead to heavy rains and floods in the region are the recult of the ctrenathening and intencification of the Sudan low-pressure center and the Red Sea Loading [MathJax]/jax/output/CommonHTML/fonts/TeX/fontdata.js 
convergence region and in some cases, from the merging of the low-pressure center of Sudan with the low-pressure center of the Mediterranean. There have been many studies on the transport of atmospheric moisture, some of which have referred to it as atmospheric rivers. According to Zhu and Newell (1998), one phenomenon related to atmospheric moisture transport is atmospheric rivers (ARs). This phenomenon, in the form of narrow corridors with a depth of $40 \mathrm{~km}$ and a width of $500 \mathrm{~km}$, and a length of several thousand kilometers, directly and indirectly, affect more than $90 \%$ of water vapor meridian transport.

Salimi and Saligheh (2016) investigated the effect of atmospheric rivers on Iran's climate. The results showed that an average of twelve atmospheric rivers is formed annually, which provides moisture to part of Iran's rainfall. Akbari et al. (2019) investigated the temporal and spatial changes of atmospheric rivers in the MENA region. The results showed that in more than $90 \%$ of the cases, the atmospheric rivers of the study area have a southwest-northeast flow. Also, the atmospheric rivers of the MENA region converge at their destination, and air suction has caused the concentration of atmospheric rivers in this region. The results showed that jet streams play a major role both in the production of atmospheric rivers and in their direction and path, and high-pressure centers have a high role in the expansion and low-pressure centers on the destination of atmospheric rivers. Areas such as the western United States, the west of southern Cape of South America, northwestern Europe, the northeastern route from Saudi Arabia to northeastern Iran, Australia, the border between Japan, and the eastern coast of Russia are also regions that are most affected by ARs rainfall.

Salimi et al. studied the origin of the world's atmospheric rivers. According to their results, there are seven main sources of atmospheric rivers in the world, the most important of which is located in Southeast Asia. In terms of monthly distribution, January, September, and October have the highest occurrence of atmospheric rivers. There is little difference in the two hemispheres in terms of the number of atmospheric river occurrences, only the ARs of the southern hemisphere have a longer longitude. In terms of the number of occurrences in the world, in most cases, 4 to 3 atmospheric rivers were observed simultaneously. Also, more than $90 \%$ of ARs travel by ocean path (Salimi et al, 2020). Due to the importance of Sudanese atmospheric and low pressure rivers on moisture transport and its effect on rainfall in Iran, in this study, the dynamics and thermodynamics of Sudan thermal low pressure in relation to the atmospheric river were investigated.

\section{Data And Methodology}

In this research, to study Sudanese low pressure over a period of 30 years, first, u wind, $v$ wind, omega, Shum, slp, monthly average of northward surface stress, daily mean precipitation rate, and temperature data were obtained from Noaa, Era interim, and Giovanni sites. Nova ncep / ncar data have a resolution of $2.5 * 2.5$ degrees, ERA Interim data have a resolution of $0.25 * 0.25$ degrees and data obtained from Giovanni site have a resolution of $0.5 * 0.625$ degrees. In this study, first, the years when the Sudanese low-pressure nucleus was visible were selected, which included 18 cases, and in terms of annual 
software. Then, in order to study the transition at near-ground level, the cold season of the year was examined monthly with monthly average of northward surface stress data of MERA-2 model, which was received from Giovanni site. These data identify the North Stream potential. Next, two samples of the atmospheric river for March 11, 2011, and March 26, 2019, were selected for the relationship between Sudanese low pressure and moisture transfer. Then, the atmospheric river map was extracted with special humidity data or Shum. An omega map was generated to study the dynamic changes of the Sudanese low pressure at the level of $600 \mathrm{hPa}$ in which the atmospheric river occurred. Omega has negative and positive values; the negative value of which indicates the ascent of air and the positive value of which indicates the descent of air. Our focus was on the altitude boundary between negative and positive omega. Also, using orbital and meridional data, a day jet stream map was generated with atmospheric river occurrence. A rainfall map of Iran was also produced for the second atmospheric river event, i.e. March 26, 2019. Omega and temperature maps were used for thermodynamic study and necessary analyzes were performed.

\section{Results}

Sudanese low pressure, like other climate patterns, is unstable and can change significantly from year to year. In the present study, the changes of Sudan thermal low pressure over a period of 30 years have been investigated (Fig. 2). During the study period, Sudanese low pressure has been observed on pressure maps for most of the years. Previous studies such as Hejazi and et al. (2020) show that the months of January, February and March had more effects on the climate of the surrounding areas, especially Iran, so these three months were selected. This low pressure was more widespread in 1996, 1999, 2006, 2009, 2011 and 2012, with 2006 being the most widespread during the study period. Quite interestingly, the Sudanese low pressure can be considered a dual-core low pressure. In most cases, two low-pressure cores were observed adjacent to each other on a horizontal axis. The unit value of pressure is equal to $1008 \mathrm{hPa}$. Although there was no significant difference in the amount of ambient pressure, in the continuation of this study, it can be seen that this small difference had many effects on the transfer of moisture to the atmosphere.

In the above figure, the blue polygon points show the thermal low pressure of the surface level. The years when low pressure had significant changes in the environment were selected.

Wind stress magnitude is the amount of force on a surface generated by winds. It is a function of drag, air density, and wind velocity, and has units of Newtons per square meter $\left(\mathrm{N} / \mathrm{m}^{2}\right)$.

Figure 3 shows the monthly average northward surface stress for the months of December, January, and February over a 30-year period with an average of four-year periods (8 periods) from 1988 to 2020. This northward stream flow provides useful information for studying the potential for atmospheric transitions near the land surface. According to the output of the maps, it can be seen that from the first period of the study, the intensity of this tension and the pressure of the currents decreased, except for a period of

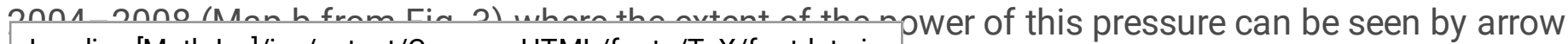
Loading [MathJax]/jax/output/CommonHTML/fonts/TeX/fontdata.js 
signs. During the study period, there is a potential for air and humidity to pass from Sudan to Iran from the Mandeb Strait to $42 \triangle$ north latitude and to the north of Iran. According to this map, the role of the dynamic atmosphere of $600-700 \mathrm{hPa}$ can be considered very important, because the transition conditions are provided at a level close to the ground and only the presence of high-level atmospheric conditions such as jet streams is necessary. In most of the maps, it can be seen that the Persian Gulf region has negative figures and north reverse traction is prevalent in it, but in most parts of Saudi Arabia, the north stream stretch is positive and has the potential for good atmospheric transfer dynamic potential to Iran. Mandeb Strait or Bab-el Mandeb has the most power of this energy.

To study the effect of Sudanese low pressure as an atmospheric moisture feeding source (Akbari et al., 2019), it is very important to study an interesting phenomenon called atmospheric rivers. Figure 4 (map a) shows the occurrence of the atmospheric river on March 11,2011. This atmospheric river exactly passed through the upper atmosphere of Sudanese low-pressure at $600 \mathrm{hPa}$. It originated in Africa, but it can be seen that in the upper atmosphere of the Sudanese low-pressure, this river has been fortified and the expansion of the atmospheric river has continued to the upper atmosphere of Iran. The omega map in the figure below examines the dynamics of the Sudanese low-pressure moisture sector. According to it, it can be said that the level of $600 \mathrm{hPa}$ is the boundary between positive and negative omega. This border is without descending or ascending movements and the horizontal movement of the air is only movable, which helps the moisture to flow to higher latitudes such as Iran. On March 11, 2011, the amount of ascending and descending movement increased to a higher level, in which case the ascending and descending movements are more static at the border between them and the horizontal movement pressure is higher.

To investigate the effects of Sudanese low pressure on Iran's precipitation and the mechanism of its formation, the atmospheric river on March 26, 2019 has been studied (Fig. 5). Exactly on this date, a jet stream occurred at the level of $300 \mathrm{hPa}$ above the Red Sea and Iran. Its speed has reached 50 meters per second, which has relatively good power. Jet streams cause suction on their underside and the high carrying capacity of atmospheric particles such as water vapor. This jet stream has caused an atmospheric river and this river, which has been created at the level of $600 \mathrm{hp}$, has transported relatively good moisture to Iran, a large part of which is provided by high humidity in Sudan and transferred by the jet stream. The amount of rainfall caused by this river has been so extensive that it has caused rainfall in more than $70 \%$ of the regions of Iran. The study of dynamic and thermodynamic changes is provided in Fig. 6.

Dynamic and thermodynamic changes and currents are the most important elements to study the Sudanese low-pressure changes $\left(10^{\circ} \mathrm{N}\right.$ and $\left.40^{\circ} \mathrm{E}\right)$ along with the atmospheric river phenomenon. Figure 6 (map a) shows the temperature changes of March 26, 2019 at four levels of 550, 650, 750 and $850 \mathrm{hPa}$. There is a temperature gradient from the surface level to the upper levels. Temperature changes have been very high compared to the days before and after. This elevation slope continued to the level of $550 \mathrm{hPa}$, roughly the same level as the March 26 atmospheric river event. Map b also confirms these 
omega nucleus, shown in blue on the map, highlights the importance of the Sudanese low-pressure transition to the atmospheric river. The level of 600, except for March 26, had positive omega values or downtrends on other days of March. Examining the $u$ wind map from Figure $c$, it can be seen that from March 25 and 26, the westerly wind flow was prevalent from 850 to about $550 \mathrm{hPa}$; This confirms the current transfer at the level of $600 \mathrm{hPa}$ in which the ascending and descending movements are neutralized. Also, according to map $d$, a northward meridional wind current is observed at this level. When two westward flows along the southern meridian run north, the final flow will form a northeastern flow.

Figure 7 shows the relationship between the Sudanese low pressure and the occurrence of the atmospheric river. One day after the formation of the strong Sudan low pressure, an atmospheric river is formed which has a flow toward Iran's atmosphere. Low pressures play an important role in strengthening transmission systems and send moisture through atmospheric rivers to remote areas and even Iran. It is worth mentioning that Saudi low pressure is also very important in transferring moisture to Iran; map b shows a small Saudi low-pressure core.

\section{Conclusion}

The climate change trend is an inevitable phenomenon in the present era; in such a way that no fundamental control can be exercised to change it except in the aspect affected by human activities. Therefore, in this process, it is important to study changes and study climatic patterns and phenomena in a more accurate way and with up-to-date data. In this study, Sudanese low pressure as an atmospheric source of feeding to rainfall systems of Iran has been investigated. Many studies have been carried out on Sudanese low pressure, but few studies have focused on dynamics and thermodynamics and its relationship with atmospheric river flow, which in this study has been well analyzed. In this regard, various sources of data such as precipitation, temperature, specific humidity, north wind flow, orbital and meridional omega winds, and mean sea level pressure were used, which were converted to a map in the grads programming software. The results of this study showed that the annual changes of Sudanese low pressure cores are different and in some years, it has had two cores. In 1996, 1999, 2006, 2009 and 2011, the expansion of thermal low-pressure core has reached its peak; And in 14 cases, it has had two cores. The average northward surface stress monthly map clearly showed that the northward flow had a good potential from the Sudanese low pressure formation zone to the upper reaches of Iran in a southwestnortheast mode and indicated that at low levels, the conditions for moisture transfer from the Sudan region to Iran are available. At the outlets of the two atmospheric rivers on March 11, 2011 and March 26, 2019 , it was found that the atmospheric river had good visibility at the level of $600 \mathrm{hPa}$, and these rivers had a good relationship with the study of omega maps and ascent and descent conditions. The altitude boundary between the ascending and descending air currents, which is usually $600 \mathrm{hPa}$, is the limit for stopping vertical currents to up and down, and the limit for starting horizontal currents. As in previous studies, atmospheric rivers are related to high-level jet streams. In this study, in the days with atmospheric rivers, jet streams prevailed at $300 \mathrm{hPa}$ above the atmospheric river, i.e. at $300 \mathrm{hPa}$. An examination of the rainfall map revealed that the atmospheric river on March 26, 2019 has affected more than $70 \%$ of Iran in 
altitudes of $850-550 \mathrm{hPa}$, a large slope occurred between the isothermal lines and the isothermal lines have failed. Also, orbital and meridional wind maps had north and east winds at an altitude of $600 \mathrm{hPa}$ which are formed in the transformation of these two types of northeastern flows with the route corresponding to the Sudan-Iran direction.

\section{Declarations}

- Conflict of Interest: The authors declare no conflict of interest

- Ethical Approval Statement: Since this study does not involve human subjects, it does not require ethical approval statement.

- Funding statement: The author(s) received no financial support for the research, authorship, and/or publication of this article.

- Consent to participate: This study did not involve human participants

- Consent for publication: all authors consent to the publication of the manuscript in Theoretical and Applied Climatology

- Availability of data and material: The data that support the findings of this study are available from the corresponding author, upon reasonable request.

- Author's Contribution: This article is extracted from a doctoral thesis.

- Code availability: Software application or custom code is not used in this research

\section{References}

1. Akbary M, Salimi S, Hosseini SA, Hosseini M. 2019.Spatio-temporal changes of atmospheric rivers in the Middle East and North Africa region. Int J Climatol,1-11. https://doi.org/10.1002/joc.6052

2. Alijani, Bohlool (1987). Mediterranean cyclonic routes. Quarterly Journal of Geographical Research, 4, 125-143.

3. Azizi, Qasem, Naieri, Masoumeh, Rostami Jalilian, Shima. (2009). Synoptic analysis of heavy rainfall in the west of the country. Natural Geographical Quarterly, 4, 1-13.

4. Alpert, P.; B.U. Neeman, and Y. Shay. 1990b. Climatological analysis of Mediterranean cyclones using ECMWF data. Dynamic Meteorology and Oceanography, 42A: 65-77. https://doi.org/10.1034/j.1600-0870.1990.00007.x

5. Alpert, P.; I. Osetinsky, B. Ziv and H. Shafir.2004.A new season definition based on classified daily synoptic system: An example for the Eastern Mediterranean. International Journal of Climatology, 24:1013-1021. https://doi.org/10.1002/joc.1037

6. Bech, J.; R. Pascual, T. Rigo, N. Pineda, N. Lopez, J.M. Aros and J. Gayà. 2014. A Mediterranean nocturnal heavy rainfall and tornadic event. Part I: Overview, damage survey and radar analysis. Atmospheric Research, 100: 1-17. https://doi.org/10.1016/j.atmosres.2010.12.024 
7. Blender, R.; K. Fraedrich, and F. Lunkeit.1997. Identification of cyclone track regimes in the North Atlantic. Quarterly Journal of the Royal Meteorology Society, 123: 727-741. https://doi.org/10.1002/qj.49712353910

8. Campins, J.; A. Jansa, and A. Genoves. 2006. Heavy rain and strong wind events and cyclones in the Balearics, Advances in Geosciences, 7: 73-77. https://doi.org/10.5194/adgeo-7-73-2006

9. Flaounas, E.; V. Kotroni, K. Lagouvardos, and I. Flaounas. 2014. CycloTRACK (v1.0)- tracking winter extratropical cyclones based on relative voracity: sensitivity to data filtering and other relevant parameters. Geoscientific Model Development, 7: 1841-1853. DOI: 10.5194/gmd-7-1841-2014

10. Flocas, H.A.; I. Simmonds, J. Kouroutzoglou, K. Keay, M. Hatzaki, V. Bricolas and D. Asimakopoulos .2010. On cyclonic tracks over the eastern Mediterranean. Journal of Climate, 23: 5243-5257. https://doi.org/10.1175/2010JCLI3426.1

11. Farajzadeh Asl, Manouchehr, Fathnia, Amanullah. Lashkari, Hassan. (2008). Routing and finding the frequency of precipitation systems in western Iran (Kermanshah and Ilam provinces). Journal of Human Sciences, 12, 139-159.

12. Irannejad, Parvin, Ahmadi-Givi, Farhang, Mohammadnejad, Alireza. (2009). The effect of Mediterranean cyclogenesis centers on annual precipitation of Iran during 1960 to 2002. Iranian Journal of Geophysics. 3(1), 91-105.

13. Hejazizadeh, Zahra, Sedaghat, Mehdi (2009). Digital routing of Middle East cyclones during the cold period of the year. Natural Geography Research, 69, 1-17.

14. Hejazizadeh Zahra, Alijani Bohlool, Saligheh Mohammad, Sayad Vahideh. 2021. Analyzing the trend and extent of Sudan low pressure and its impact on precipitation in western and southwestern Iran. Arabian Journal of Geosciences.;14(4):295. 10.1007/s12517-021-06452-5

15. Kelemen, F. D.; J. Barthily, and R. Pongracz. 2014. Multivariable cyclone analysis in the Mediterranean region. Quarterly Journal of the Hungarian Meteorological Service, 2: 159-184.

16. Khosravi, Mahmoud, Nazaripour, Hamid. (2010). Application of cluster analysis in identifying the characteristics of rainy days in Khash station. Geographical space, 31, 65-90.

17. Lashkari, Hassan. (2002). Tracking Sudanese Low Systems Entering Iran. MJSP, 6 (2), 133-157.

18. Lashkari, Hassan, Asgharpour, Monireh, Motakan, Ali Akbar. (2008). Synoptic analysis of floodcausing factors in Golestan province. Quarterly Journal of Human Sciences, 2, 181-201.

19. Mehmet, K.; D. Ali, and T. Mete .2004. Cyclone Track Variability over Turkey in Association with regional Climate. International Journal of Climatology, 20: 1225-1236.

https://doi.org/10.1002/1097-0088(200008)20:10\%3C1225::AID-JOC535\%3E3.0.C0;2-1

20. Mofidi, Abbas, Zarrin, Azar. (2005). Synoptic study of the effect of Sudanese low pressure systems on the occurrence of floods in Iran. Journal of Geographical Research, 77, 113-136.

21. Neu, U.; M. G. Akperov, N. Bellenbaum, R. Benestad, R. Blender, R. Caballero, A. Cocozza, H. F., Dacre, Y. Feng, K. Fraedrich, J. Grieger, S. Gulev, J. Hanley, T. Hewson, M. Inatsu, K. Keay, S. F. Kew, I. Kindem, G. C. Leckebusch, M. L. R. Liberato, P. Lionello, I. I. Mokhov, J. G. Pinto, C. C. Raible, M. Reale, I. 
Ulbrich, X. L. Wang, and H. Wernli.2013. A Community Effort to Intercompare Extratropical Cyclone Detection and Tracking Algorithms, Bulletin of the American. Meteorological Society, 94: 529-547. https://doi.org/10.1175/BAMS-D-11-00154.1

22. Picornell, M. A.; A. Jansa, A. Genoves, and J. Campins. 2001. Automated database of mesocyclones from the HIRLAM (INM) 20.58 analyses in the Western Mediterranean. International Journal of Climatology, 21: 335-354. https://doi.org/10.1002/joc.621

23. Parandeh Khozani, Akram, Lashari, Hasan (2010). Synoptic Analysis of Flood Generating Systems in the Southern Part of Iran. Iran water resources research, 2, 66-73.

24. Ramis, C.; R. Romero, V. Homar, S. Alonso, and M. Alarcon. 1998. Diagnosis and numerical simulation of a torrential precipitation event in Catalonia (Spain), Meteorology and Atmospheric Physics, 69: 1-21. https://doi.org/10.1007/BF01025180

25. Reale, M. and P. Lionello. 2013. Synoptic Climatology of winter intense precipitation events along the Mediterranean coasts. Natural Hazards and Earth System Sciences, 13: 1707-1722.

Doi://10.5194/nhess-13-1707-2013

26. Romem, M.; B. Ziv, and H. Saaroni. 2007. Scenarios in the development of Mediterranean cyclones, Advances in Geosciences, 12: 59-65. Doi://10.5194/adgeo-12-59-2007.

27. Rudeva I. and S. K. Gulev. 2007. Climatology of cyclone size characteristics and their changes during the cyclone life cycle. Monthly Weather Review, 135: 2568-2587. https://doi.org/10.1175/MWR3420.1

28. Salimi, S. and Salighe, M. (2016) The effects of atmospheric rivers on Iran climate. Physical Geography Research Quarterly, 48(2), 247-264. Doi: 10.22059/JPHGR.2016.59366.

29. Salimi, S., Helali, J., Lotfi, M. Momenzadeh, H., Hosseini, S A., Asaadi Oskuei, E., Izadi, A., Yarmoradi, Z., Bakhshi E(2020). Investigating the origin and pathways of atmospheric rivers in the world. Theor Appl Climatol 142, 165-175. https://doi.org/10.1007/s00704-020-03299-w

30. Simmonds, I.; C. Burke, and K. Keay. 2008. Arctic climate change and manifest in cyclone behavior, Journal of Climate, 21: 5777-5796. https://doi.org/10.1175/2008JCLI2366.1

31. Smagorinsky, J. 1950. Some aspects of the general circulation. Royal Meteorology Society, London, 120-155. https://doi.org/10.1002/qj.49709038302.

32. Trigo, I. F. 2006. Climatology and interannual variability of storm-tracks in the Euro- Atlantic sector: a comparison between ERA-40 and NCEP/NCAR reanalyses, Climate dynamics, 26: 127-143. https://doi.org/10.1007/s00382-005-0065-9

33. Ulbrich, U.; G. C. Leckebusch, and J. G. Pinto.2009. Extra-tropical cyclones in the present and future climate: a review, Theoretical and Applied Climatology, 96: 117-131. https://doi.org/10.1007/s00704-008-0083-8

34. Whitaker, L. M. and L. H Horn. 1984. Northern hemisphere extratropical cyclones activity for four midseason months. Journal of Climatology. 4: 297-310. https://doi.org/10.1002/joc.3370040307 


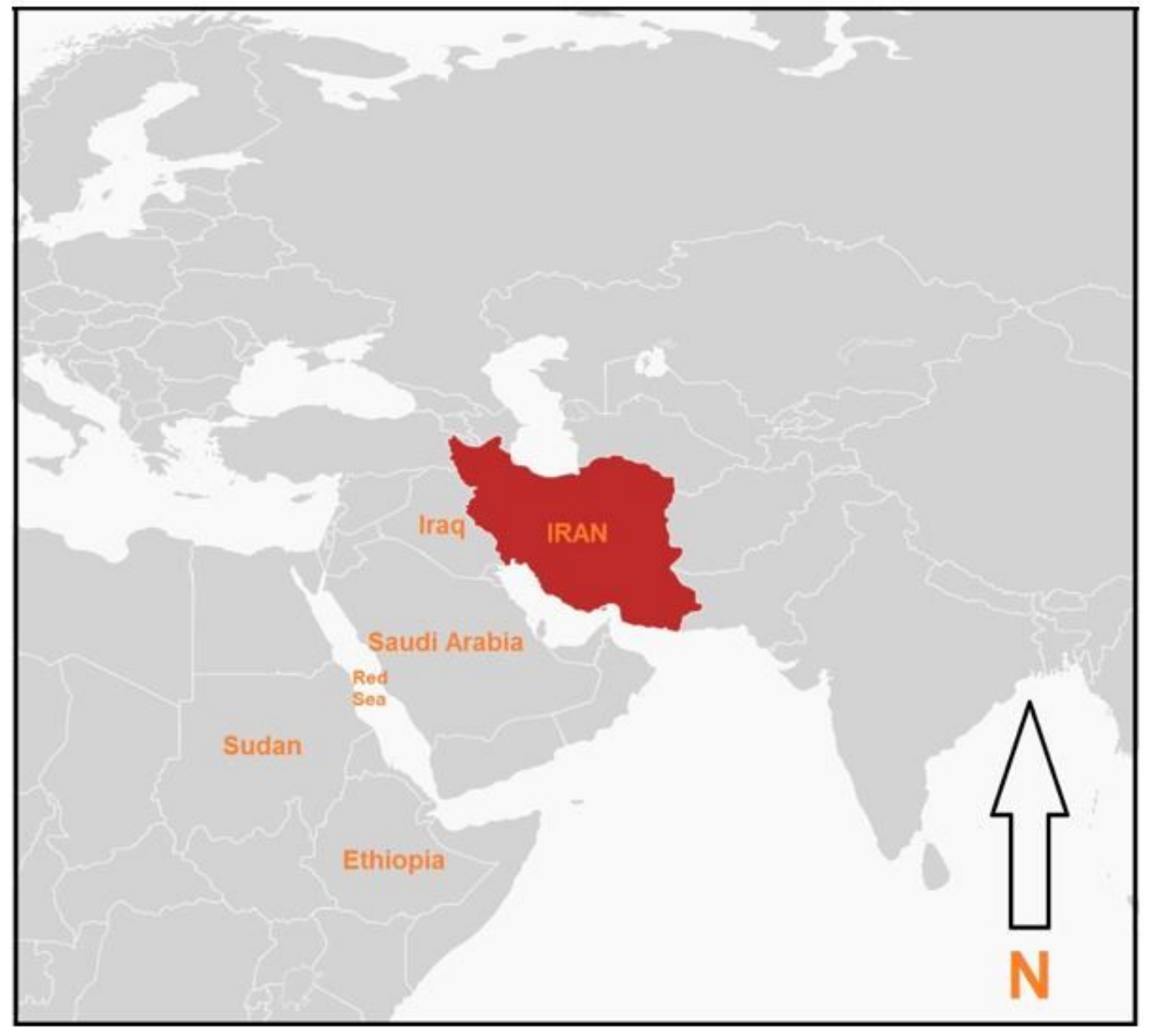

\section{Figure 1}

The map of the study area. Note: The designations employed and the presentation of the material on this map do not imply the expression of any opinion whatsoever on the part of Research Square concerning the legal status of any country, territory, city or area or of its authorities, or concerning the delimitation of its frontiers or boundaries. This map has been provided by the authors. 

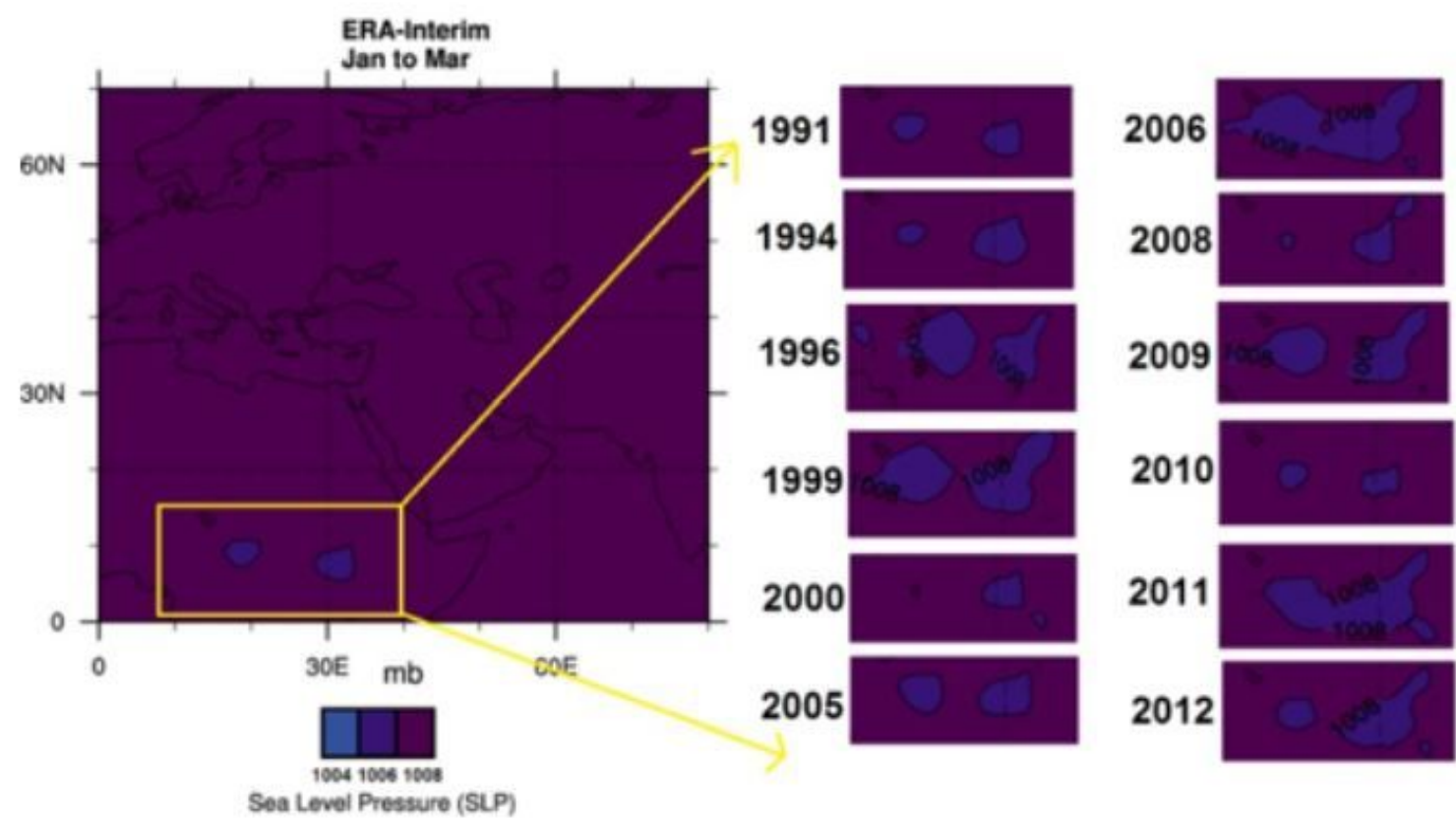

(1)

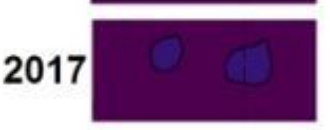

2018

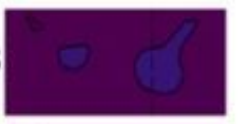

2019

\section{Figure 2}

Monthly average map of sea level pressure from January to March, over a period of 30 years (19902020). Note: The designations employed and the presentation of the material on this map do not imply the expression of any opinion whatsoever on the part of Research Square concerning the legal status of any country, territory, city or area or of its authorities, or concerning the delimitation of its frontiers or boundaries. This map has been provided by the authors. 

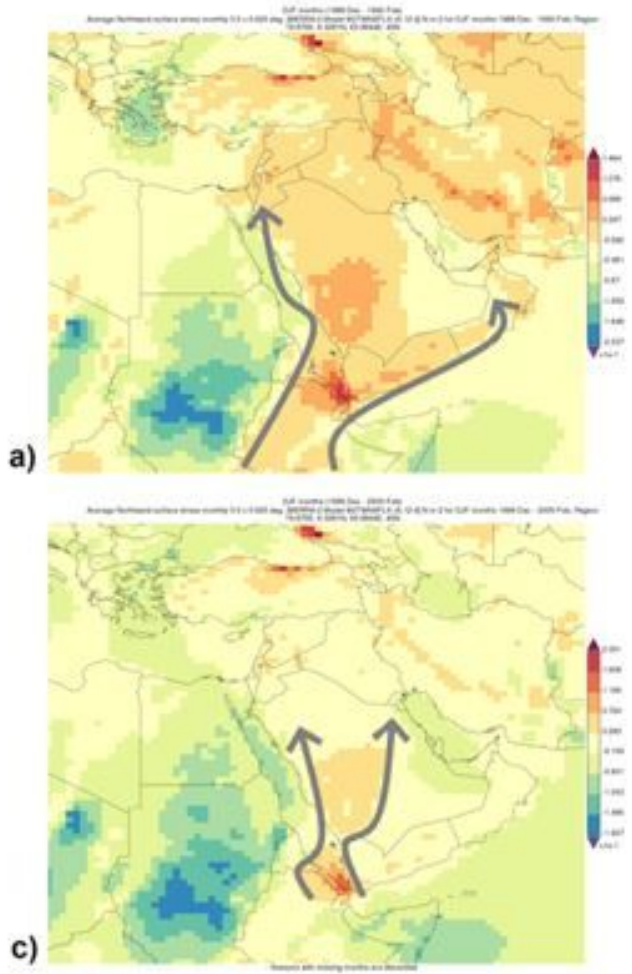

b)
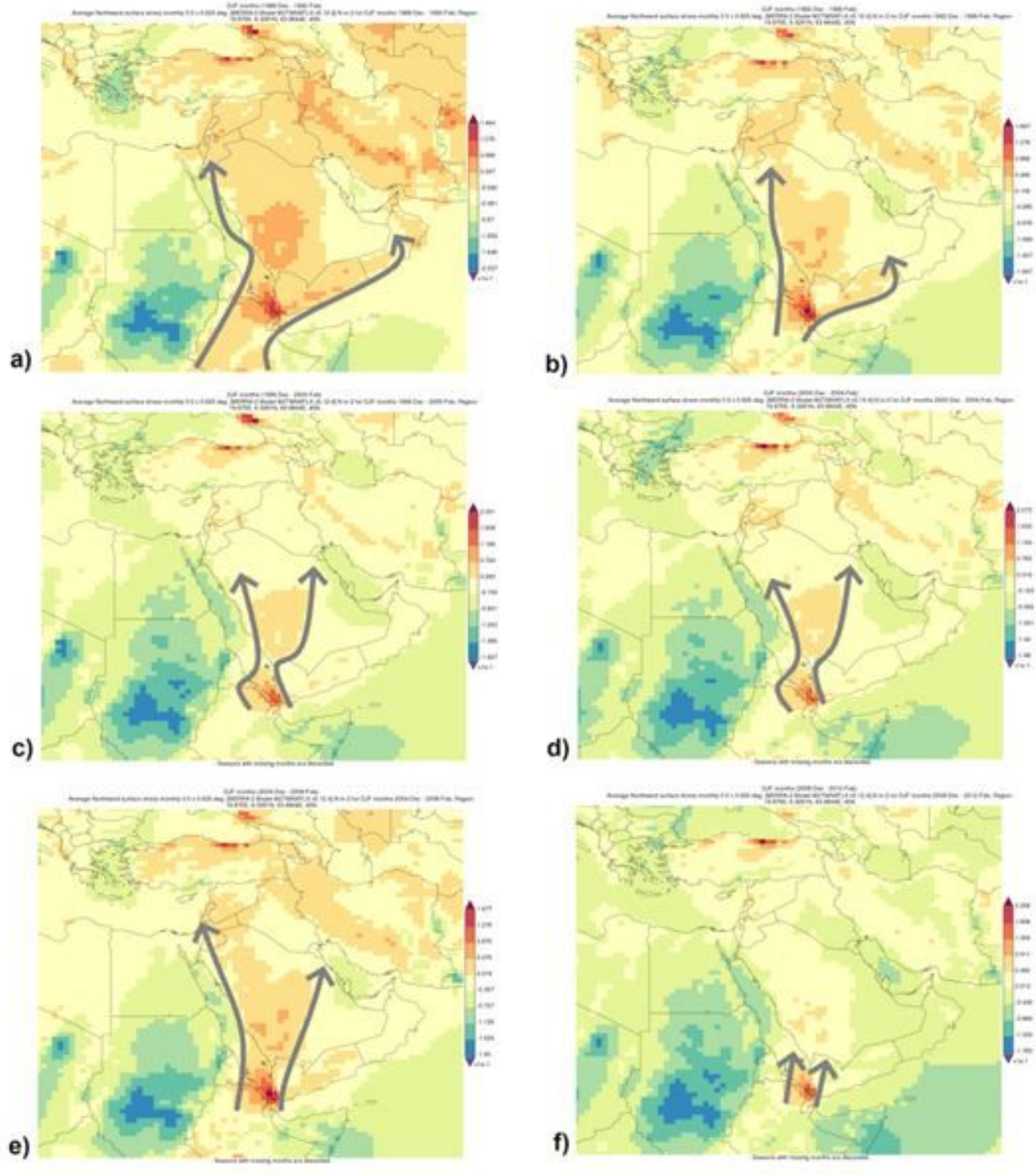

d)
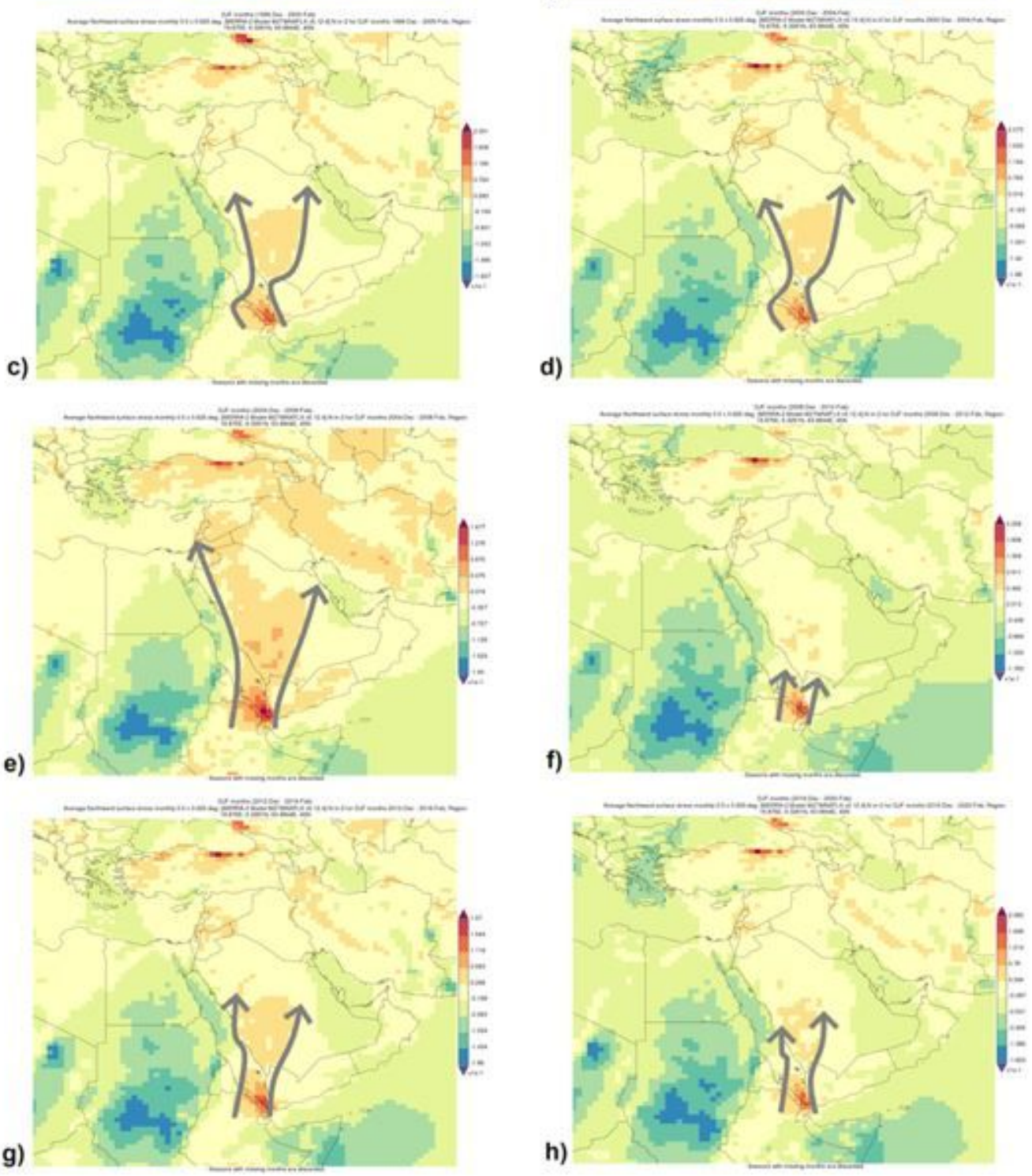

\section{Figure 3}

monthly average northward surface stress during the months of December-January-February of the years a: 1988-1992, b: 1992-1996, c: 1996-2000, d: 2000-2004, e: 2004-2008, f: 2008-2012, g: 2012- 2016, h: 2016-2020. Positive numbers indicate north stretch and negative numbers indicate north reverse stretch. Note: The designations employed and the presentation of the material on this map do not imply the Loading [MathJax]/jax/output/CommonHTML/fonts/TeX/fontdata.js arch Square concerning the legal status of any 
country, territory, city or area or of its authorities, or concerning the delimitation of its frontiers or boundaries. This map has been provided by the authors.

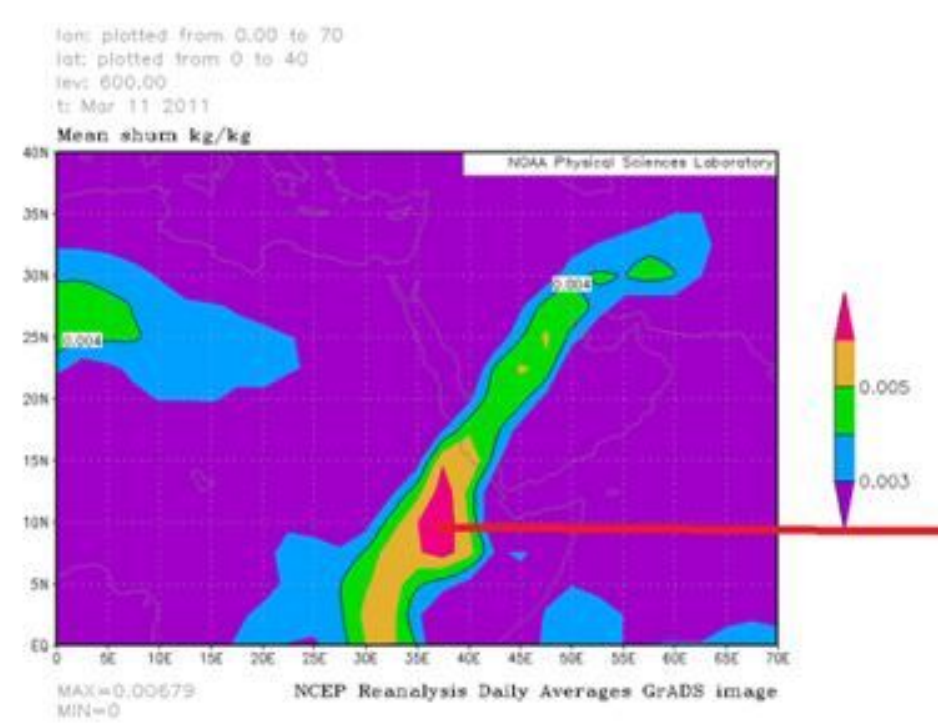

a)

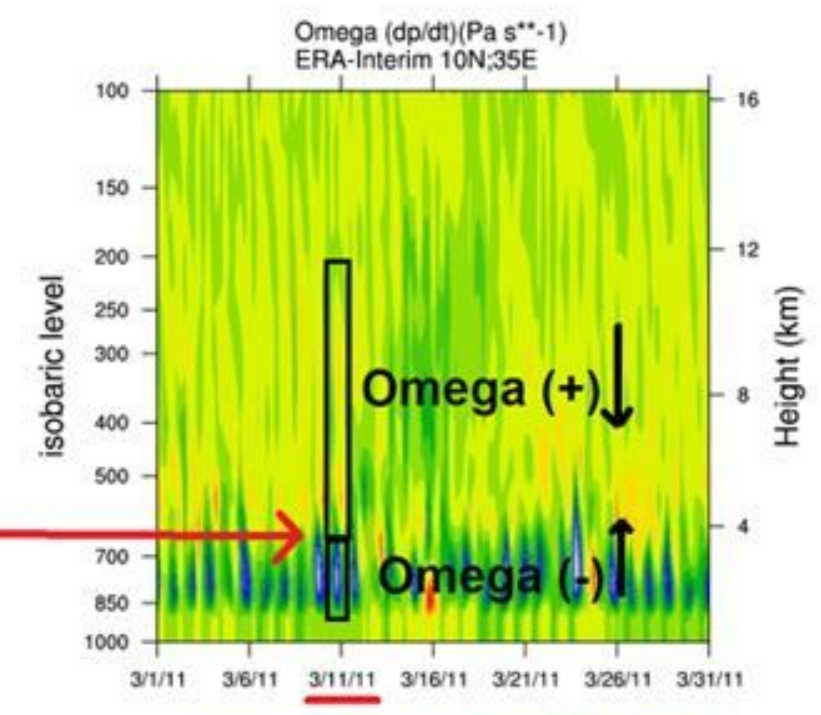

b)

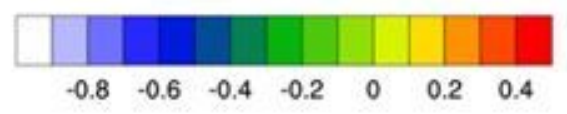

\section{Figure 4}

Atmospheric river map of March 11, 2011 (map a) and omega profile map for March 2013 (map b). The omega map is projected from the surface level up to $100 \mathrm{hp}$. The negative points show the air rise and the positive points show the air descent. The Atmospheric River Map has been selected for March 11, 2011 , to study the effect of Sudanese low pressure on Iran's climate. Note: The designations employed and the presentation of the material on this map do not imply the expression of any opinion whatsoever on the part of Research Square concerning the legal status of any country, territory, city or area or of its authorities, or concerning the delimitation of its frontiers or boundaries. This map has been provided by the authors. 

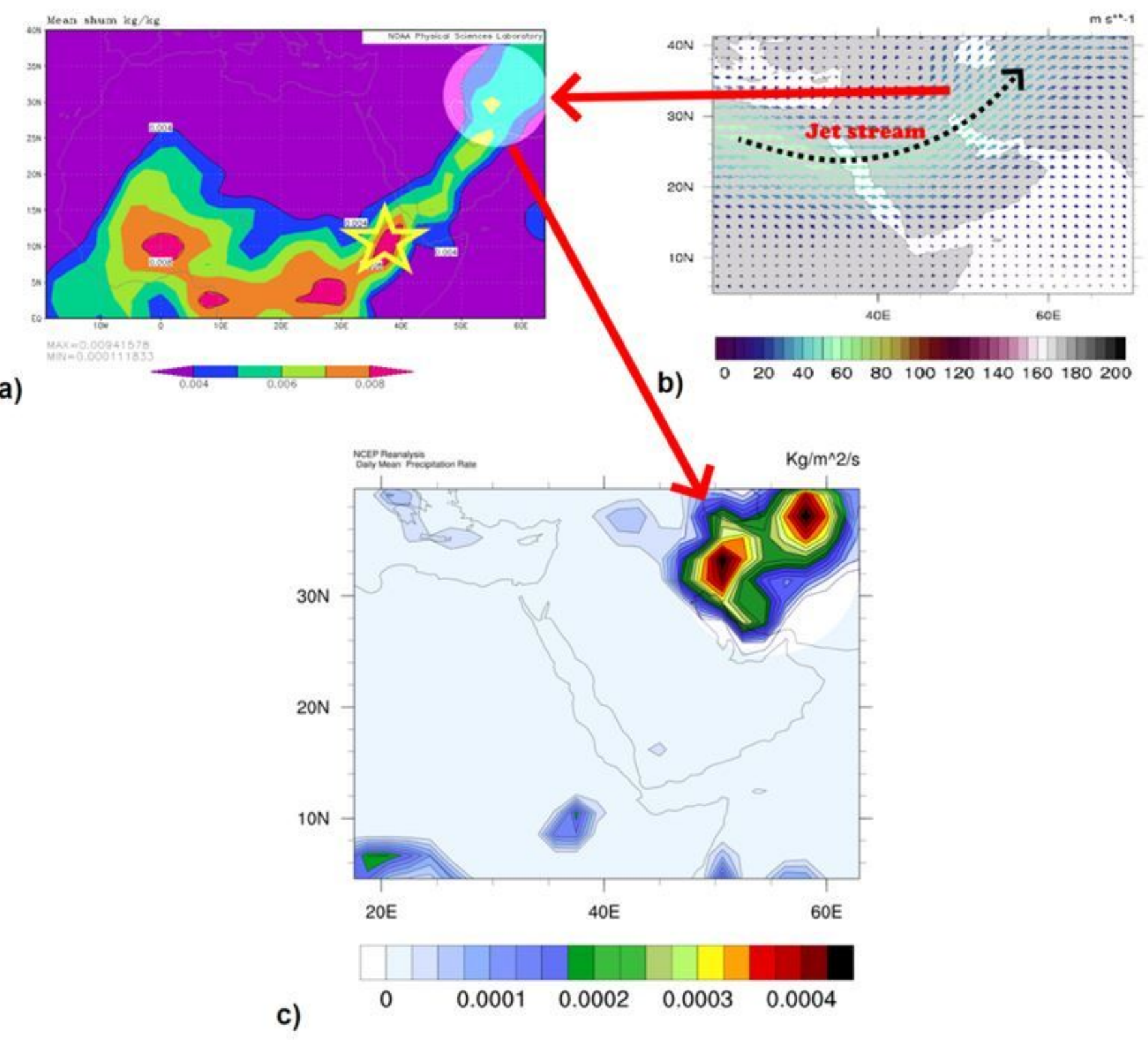

Figure 5

Atmospheric river map, March 26, 2019, level $600 \mathrm{hPa}$ (map a). Wind and jet stream map of $300 \mathrm{hPa}$ on the mentioned date. The dashed black arrow indicates the direction of the jet stream (Map b). Map of the average daily rainfall on this date above Iran (Map c). Note: The designations employed and the presentation of the material on this map do not imply the expression of any opinion whatsoever on the part of Research Square concerning the legal status of any country, territory, city or area or of its authorities, or concerning the delimitation of its frontiers or boundaries. This map has been provided by the authors. 

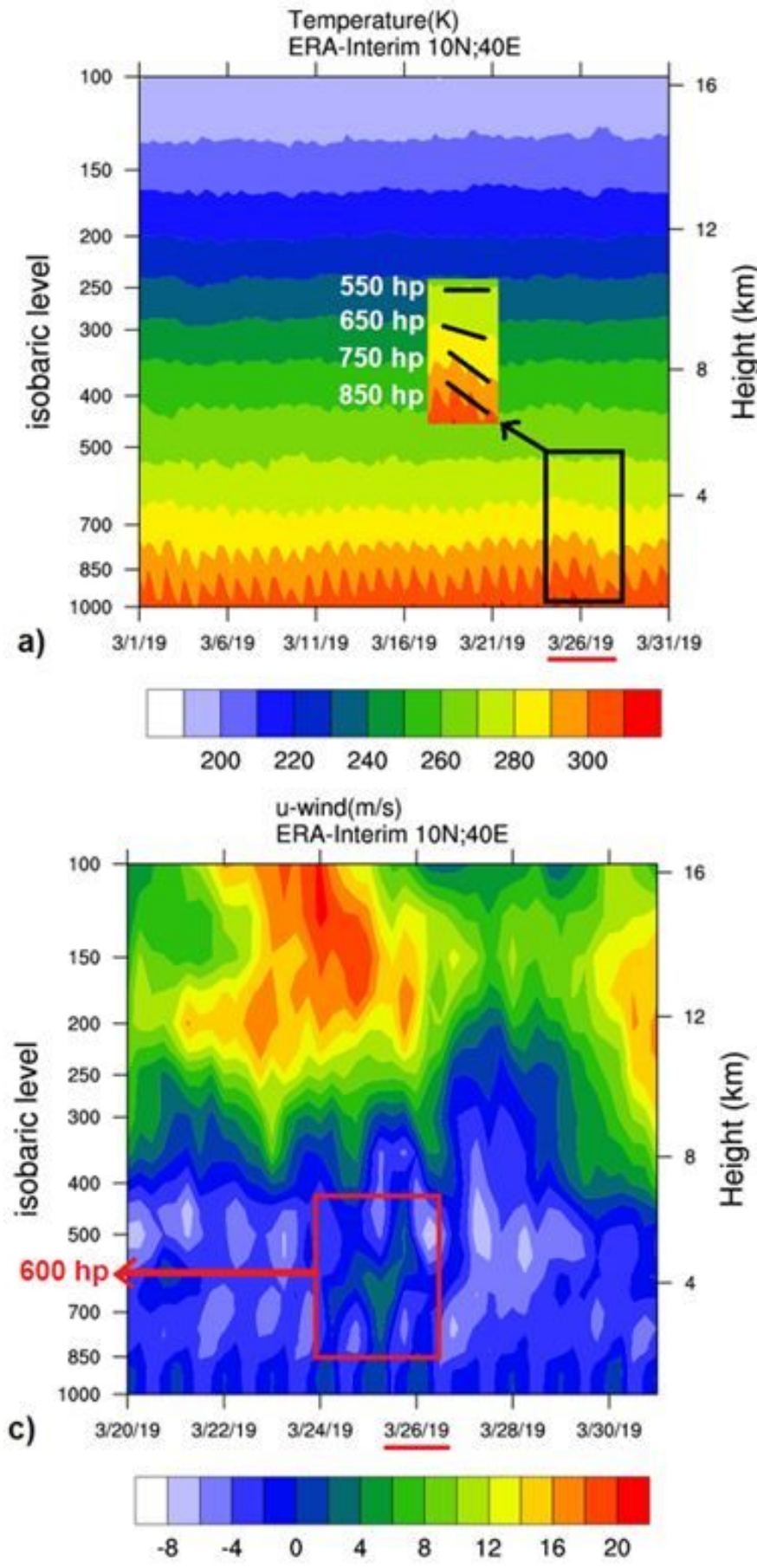
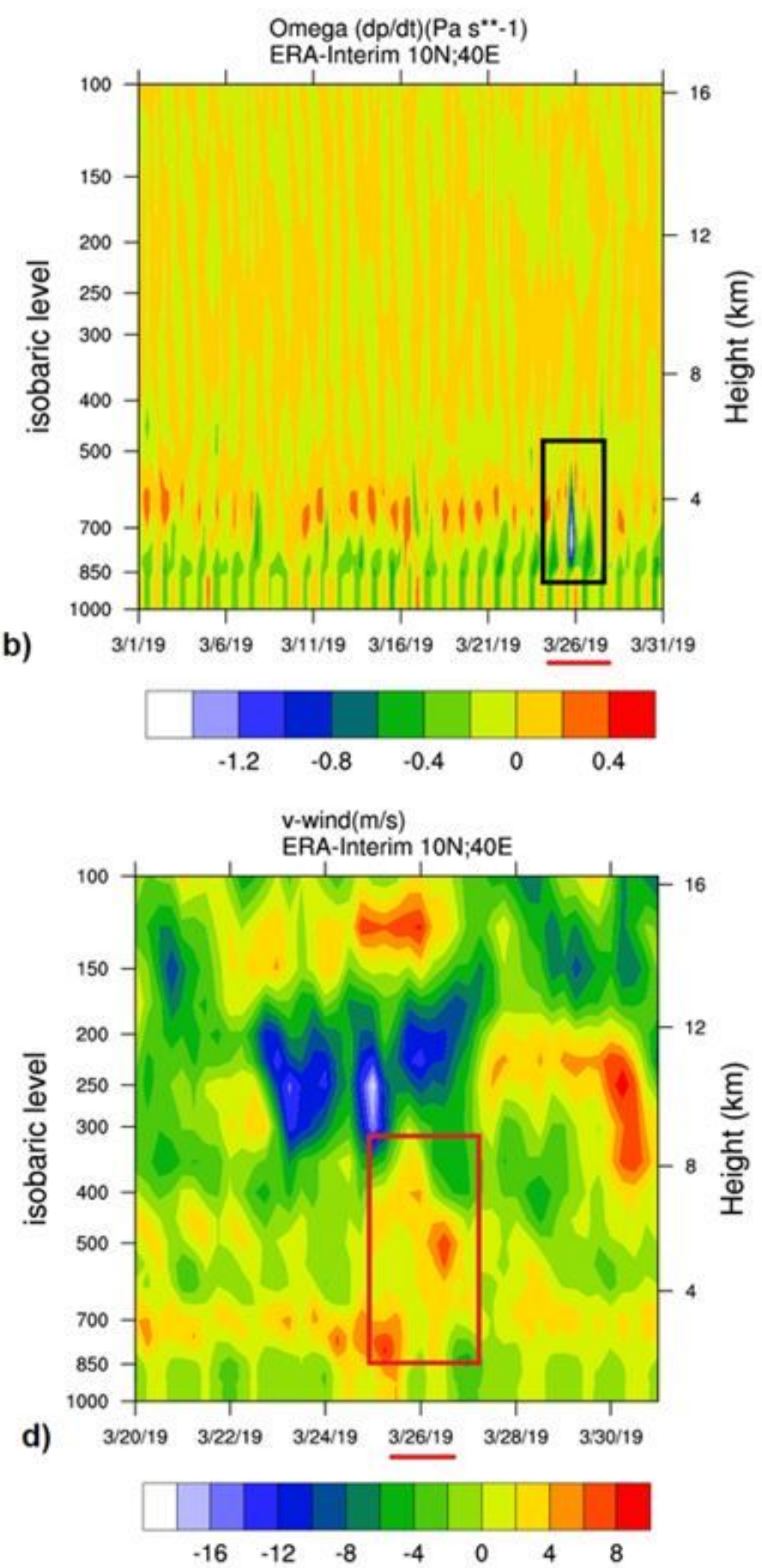

\section{Figure 6}

Profile map of temperature changes (map a) and omega changes (map b) in different levels for $10 \mathrm{~N}$ and 40E coordinates in March 2019. Wind orbital profile map (map c) and meridional (map d) in different levels from December 20 to December 30, 2019. The rectangular box inside each map shows changes in the elevation of $600 \mathrm{hPa}$ elements for the day of the occurrence of the atmospheric river in the atmosphere of the Sudanese low-pressure region. 


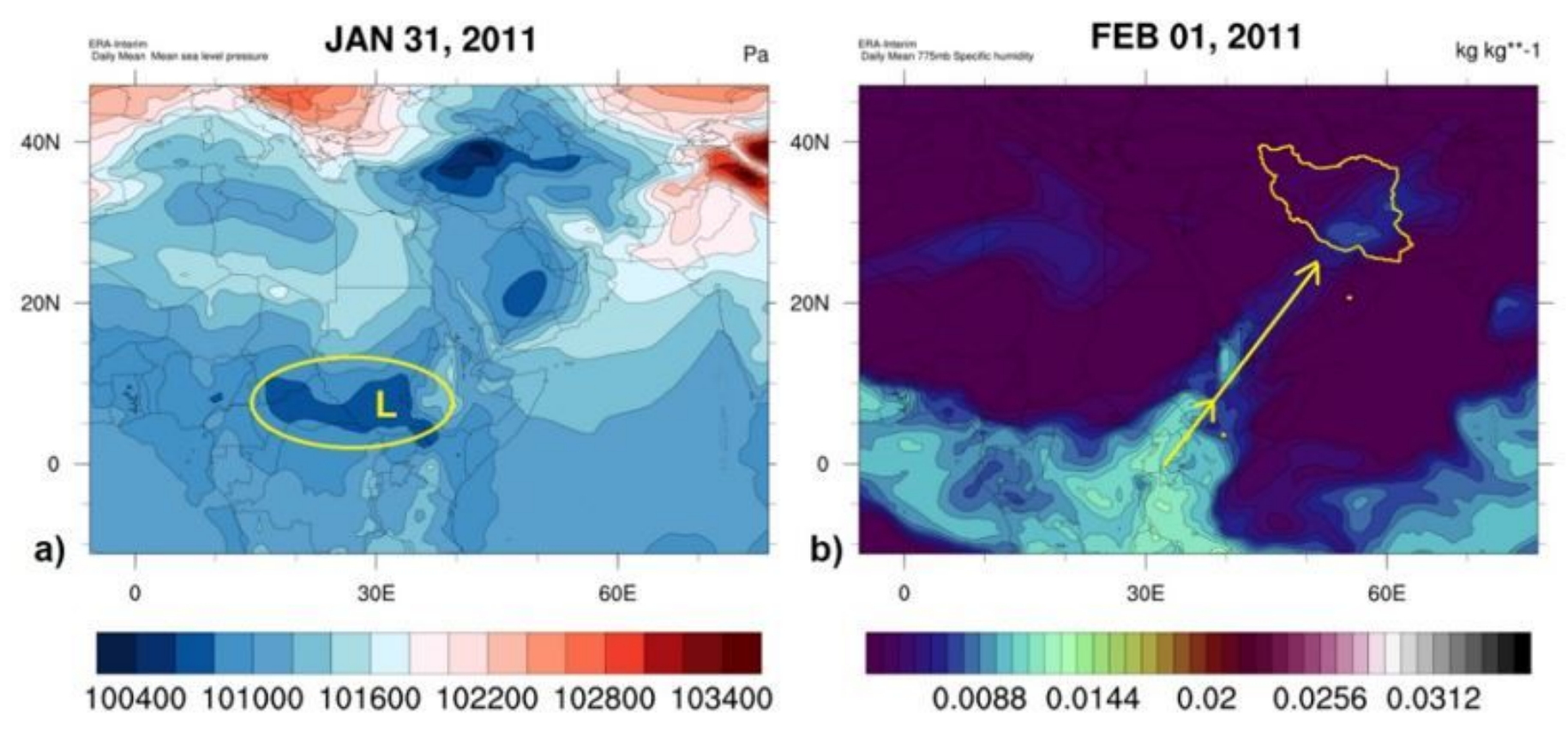

\section{Figure 7}

low-pressure sea level map for January 31, 2011 (map a), and atmospheric river map for February 1, 2011 (map b). Note: The designations employed and the presentation of the material on this map do not imply the expression of any opinion whatsoever on the part of Research Square concerning the legal status of any country, territory, city or area or of its authorities, or concerning the delimitation of its frontiers or boundaries. This map has been provided by the authors. 